\title{
En Uygun Güzergâh Algoritması ile Doğa Yürüyüşü Rotalarının Modellenmesi
}

\author{
Serdar SELIM*1
}

1Akdeniz Üniversitesi, Fen Fakültesi, Uzay Bilimleri ve Teknolojileri Bölümü, 07058, Antalya, Türkiye

(Alınış / Received: 18.05.2019, Kabul / Accepted: 30.07.2019, Online Yayınlanma / Published Online: 30.08.2019)

\begin{abstract}
Anahtar Kelimeler En uygun güzergâh analizi,

Alternatif turizm, Doğa yürüyüşü, Rota planlama, Dijkstra algoritması, CBS
\end{abstract}

Özet: Türkiye'nin en önemli turizm destinasyonlarının başında gelen Antalya ili, alternatif turizm olanakları kapsamında oldukça zengindir. Topoğrafik yapısı, iklimi, bitki örtüsü, yaban hayatı varlığı, jeolojik ve jeomorfolojik özellikleri, bölgeyi alternatif turizm açısından çeşitlendirmekte ve turistlerin ilgisini çekmektedir. Dolayısıyla bölgedeki alternatif turizm faaliyetlerinin belirlenmesi, haritalandırılması ve planlanması önem taşımaktadır. Bu çalışmada, Türkiye'nin en önemli milli parklarından biri olan ve Termessos Antik Kenti'ne ev sahipliği yapan Güllük Dağı Milli Parkı'nın, doğa yürüyüşüne uygun yollarının CBS ile modellenmesi amaçlanmıştır. Doğal ve kültürel değerlerin yerinde gösterilmesini amaçlayan ve aynı zamanda bir spor faaliyeti olan doğa yürüyüşleri, bölgedeki doğal yapıyı bozmayan önemli bir alternatif turizm faaliyetidir. Çalışma, Güllük Dağı Milli Parkı ve bu park içinde bulunan Termessos Antik Kenti'nin doğa yürüyüşleri kapsamında ulaşılabilirliğine odaklanmaktadır. Klasik turizm rotalarının oluşturulmasına alternatif olarak, hızlı ve doğru sonuçlar üreten CBS teknolojileri ile en uygun yürüyüş yollarının belirlenmesi ve haritalandırılması bu çalışmanın hedefidir. Bu kapsamda bölgenin sayısal görüntüleri üretilmiş ve bu görüntüler en uygun güzergâh (Least Cost Path) analizine tabi tutulmuştur. Bölgedeki eğim faktörü dikkate alınarak yürüyüş için uygun eğime sahip alanlar belirlenmiş, başlangıç ve bitiş noktaları arasında yürüyüş yolları oluşturulmuştur. Sonuç olarak, Milli Parktaki Termessos Antik Kenti'ne, mevcut yürüyüş güzergâhı dışında alternatif güzergâhlar belirlenmiş ve haritalandırılmıștır. Bu çalışma ile doğal yapıya zarar vermeden bölgenin tanıtılması, uygun yürüyüş güzergâhların oluşturulması, alternatif turizmin desteklenmesi hedeflenmiş, bölgeye yönelik yapılacak planlamalarda kullanılabilecek bir model önerisi geliştirilmiştir.

\section{Modeling of Hiking Routes Using the Least Cost Path Algorithm}

\section{Keywords}

Least cost path analysis,

Alternative tourism, Hiking,

Route planning, Dijkstra algorithm, GIS

\begin{abstract}
Antalya province, which is one of the most important tourism destinations of Turkey, has a very high potential scope of alternative tourism facilities. The topographic structure, climate, vegetation, wildlife, geological and geomorphological structures of the province vary in terms of alternative tourism and the region attracts tourists. Therefore, it is important to identify, mapping and planning of alternative tourism activities in the region. In this study, it is aimed to model the suitable hiking routes with GIS of Güllük Mountain National Park which is one of the most important national parks and includes Termessos Antique City. Hiking, which aim to show the natural and cultural assets on the spot and are also a sportive activity, is an important alternative tourism activity that does not damage the natural structure in the region. The study focuses on the accessibility of Güllük Mountain National Park and Termessos Antique City within this park. The objective of this study is to identify and map the most suitable hiking routes with GIS technologies that produce fast and accurate results as an alternative to the creation of tourism routes by traditional methods. Within this scope, digital images of the region were produced and Least Cost Path analysis was applied to these images. Considering the inclination factor in the region, areas with suitable slope for hiking were identified and routes were formed between the starting and ending points. As a result, alternative routes to the Termessos Antique City in the National Park, were identified and mapped. With this study, it is aimed to introduce the region without damaging the natural structure, to create suitable hiking routes and to support alternative tourism. In addition, a model proposal was developed that can be used in planning strategy for the region.
\end{abstract}




\section{Giriş}

Alternatif turizm, klasik kitle turizmine karșı olarak geliştirilmiș alternatif turizm türleri ile ilgilenen [1] ve 2000'li yıllardan itibaren sürdürülebilirlik kavramıla birlikte talebi giderek artan [2] bir turizm çeşidi olarak, gelişmiş ve gelişmekte olan ülkelerin en önemli gündemlerini oluşturmaktadır. $\mathrm{Bu}$ turizm çeşidinde bölgelerin gizli kalmış doğal güzelliklerinin ve öğelerinin korunarak kullanılabilir olması hedeflenmektedir. Günümüz turist beklentileri, geçmişteki monoton kum-deniz-güneş talebinden ziyade daha bilinçli olarak doğa ile iç içe olma, iletişim kurma ve doğala yönelme eğilimindedir [3]. Turistlerin beklentilerindeki bu farklılaşma, kaliteli çevreye, doğal ve kültürel öğelere, çok bilinenin aksine bilinmeyene doğru turistik aktiviteleri çeşitlendirmektedir [4]. Doğal ortama, sosyal değerlere ve yerel halkın yaşam biçimine uyum gösteren, hem ziyaretçilerin hem de yerel halkın deneyimlerini paylaşmalarını sağlayan [5] alternatif turizm, bölgesel ve yerel ölçekte maddi ve manevi olarak çok büyük kazanımlar sunmaktadır [6]. Bu kapsamda başta doğa yürüyüşleri (hiking) olmak üzere, yamaç paraşütü, kuş gözlemciliği, dağ bisikleti, rafting, kamping vb. gibi doğa ile özdeşleşen turizm aktiviteleri önem kazanmaktadır.

Kitle turizminin ve şehir turizminin kentler üzerindeki nüfus baskısını ve olumsuz etkilerini azaltmak için bir yenilenme olarak görülen bu tip alternatif turizm aktiviteleri, belirli bir plan ve program dâhilinde, stratejik politikalar ile kitle turizmi arasında yerini almalıdır. Ülke-bölge-yöre üçlüsünün siyasi ve politik olarak ortak kararları ile yerel ölçekte uygulanabilir olmalıdır. Bu kapsamda her bir alternatif turizm faaliyeti için, ilgili disiplinlerin ortak çalışması ile stratejik planlamalar yapılmalıdır [7]. Hangi faaliyetin hangi bölgede yapılacağı, ne gibi altyapıya ihtiyaç duyacağl, hangi kaynakları kullanacağı ve hangi kaynakları etkileyeceği [8], getiri-götürü dengesi, gibi birçok soruya cevap üretilerek planlamalar faaliyete geçirilmelidir. Doğal ekosistem değerlerine zarar vermeden bu değerlerin sergilenmesinde önemli bir paya sahip olan doğa yürüyüşleri, bir alternatif turizm çeşidi olarak büyük talep görmektedir [9]. Ekolojik - kültürel öğeleri tanitma, tarihi dokulara tanıklık etme ve aynı zamanda sağlıklı yaşamın da bir parçası olarak yürüyüş yapma, bu turizm aktivitesini sürekli canlı tutan özelliklerdendir [10]. Buna bağlı olarak peyzaj ve doğal yaşam deneyimlerinin, insanın fiziksel ve psikolojik sağlığını arttırıcı nitelikleri göz önüne alındığında [11], doğa yürüyüşü, özellikle kırsal alanlarda, sağlıklı yaşam kaynağına başarılı bir şekilde entegre edilebilen bir aktivite olarak ön plana çlkmaktadır. Doğa yürüyüşlerinin amaçlarına ulaşllabilmesi için güzergâhlarının doğru planlanması/oluşturulması esastır. $\mathrm{Bu}$ güzergâhlar için bir strateji belirlenmeden önce, ilgili faaliyetin hangi amaçlara hizmet edeceği, süresi, uzunluğu gibi özelliklerinin açık bir şekilde anlaşılması gerekir [12]. Çünkü bu özellikler, yürüyüş rotası planlamada arazinin diğer özellikleri ile (eğim, bakı, taşlılık, bitki örtüsü vb.) bir denge olușturması, uyum içerisinde olması gerekir. Gerek arazi özelliklerinin gerekse de faaliyet türünün ilgili özelliklerinin bir sistem içerisinde amaca yönelik depolanması, yorumlanması ve analiz edilmesi, planlamanın temelini oluşturmaktadır [13]. Rota planlama çalıșmaları, coğrafi bilgi sistemleri (CBS) teknolojilerindeki gelişmelere paralel olarak hızlı bir gelişme göstermiş, çeşitli algoritmalar ile çok sayıda ölçütü birlikte analiz edilebilmeyi kolaylaştırmıştır [14, 15]. Temelde rota planlama algoritmaları, birbirinden ayrı iki nokta arasındaki optimum yolu bulmaya çalışır [16], burada optimum yolu bulmak üzere birçok ölçüt, önem derecelerine göre ağırlıklandırılarak analize dahil edilir. Çoğu durumda en uygun güzergâh, mesafe ve zamanla ilgilidir [17]. Zaman, mesafe ve güzergâh tahminlerinin güvenilir ve uygulanabilir olması için, ilgili faktörlerin dikkatlice değerlendirilmesini ve analiz edilmesi gerekir. Yürüyüş rotası planlamak üzere ihtiyaç duyulan bu analizler, girdilere bağlı olarak hızlı ve doğru sonuçlar üreten CBS teknolojileri ile çözümlenebilmektedir.

Bu çalışmada, kitle turizmi bakımından Türkiye'nin öncü kenti olan Antalya İli sınırları içerisindeki dünyaca ünlü Termessos Antik Kenti'ne ev sahipliği yapan Güllük Dağı Milli parkı özelinde CBS'ye dayalı olarak otomatik doğa yürüyüșü rotaları oluşturulması amaçlanmaktadır. Milli Parktaki Termessos Antik Kenti varış noktası olmak üzere, 3 farklı başlangıç noktasından en uygun güzergâh ile ulaşımın planlanması hedeflenmiştir. Bölgenin doğaltarihi ve kültürel değerlerine zarar vermeden bölgeyi tanıtmak ve gezdirmek üzere CBS tabanlı bir yöntem kullanılmış ve girdiler bu yöntemle analiz edilmiștir. Bölgenin Milli Park olarak ilan edilmesindeki en önemli faktörün, Termessos Antik Kenti'nin bu bölgenin zirvesine yakın bir bölgede bulunuyor olması sebebiyle, başlangıç noktalarından Antik kent varıș noktasına bölgenin doğa yürüyüșüne en uygun eğim sınıfları kullanılarak güzergâhlar belirlenmiştir. Çalışmada kullanılan yöntem, bölgede kuş gözlem ve yamaç paraşüt alanlarına yürüyerek ulaşım, bisiklet rotaları gibi eğime ve yürüyüşe dayalı birçok alternatif turizm faaliyetinin planlanması için uygulanabilir niteliktedir. Dolayısıyla bu çalışma, bölgedeki alternatif turizm olanaklarını canlandırması, yöntemin diğer faaliyetler için pratik, etkin ve kullanılabilir olması sebebiyle yaygın etkiye sahiptir.

\section{Materyal ve Metot}

\subsection{Materyal}

Çalışmanın ana materyalini Güllük Dağı Milli Parkı ve Termessos Antik Kenti oluşturmaktadır. 6.702 
hektarlık alan üzerinde kurulan milli park, Toros dağlarının eteklerinde, $37^{\circ} 00^{\prime} 59.52 \mathrm{~K}-30^{\circ} 30^{\prime} 48.70 \mathrm{D}$ koordinatlarında ve Korkuteli ilçe sınırlarında yer alır. Türkiye'nin en iyi korunmuş antik şehirlerinden olan Termessos ise Antalya'nin 30 kilometre kuzeybatısında, deniz seviyesinden ortalama 1.150 metre yükseklikte, Güllük Dağı'nın güneybatısında doğal bir platform üzerine kurulmuştur (Şekil 1).

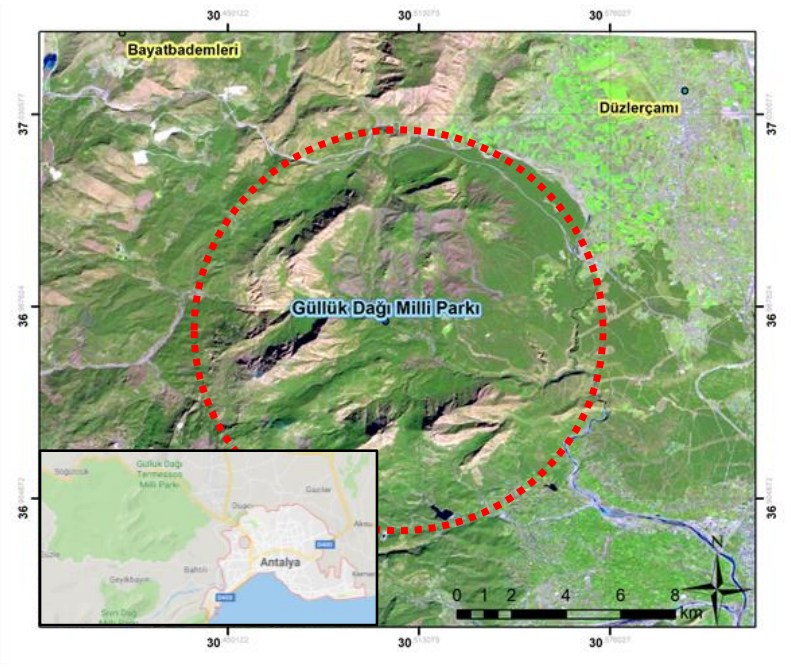

Şekil 1. Çalışma alanı konumu

Bölgede 113 kuş türü, 20 sürüngen, birçok memeli hayvan türü barınmaktadır. Milli parkta, orman ve maki örtüsü içerisinde sakız ağacı, yabani zeytin, sandal, keçiboynuzu, defne, tespih vb. 680 bitki türünün 80 (\%11.76) adedi Türkiye endemiği olarak tanımlanmaktadır. Dağ Ekosistemi; 250-1665m. Kızılçam orman, Akdeniz maki vejetasyon ve kayalık bölgelerden oluşmaktadır [18].

Arkeolojik değerleri kapsamında günümüze kadar en iyi muhafaza edilmiş şehirlerin başında Termessos gelmektedir. Bölgede Hellenistik dönemin ve Roma döneminin birçok kalıntısı ve ayakta duran birçok eseri bulunmaktadır. Surlar, sarnıçlar, karışık drenaj sistemleri, kuleler, yollar, agora, tiyatro, gymnasium ve mezarlar antik kentin en görkemli ve en çok ziyaret edilen yapılarıdır [19].

Çalışmada yardımcı materyal olarak, RGB ve NIR bantlarında 10 m mekânsal çözünürlüklü Sentinel 2A uydu görüntüsü ve ASTER GDEM (küresel sayısal yükseklik modeli) kullanılmıștır. Verilerin hazırlanması ve analize hazır hale getirilmesi işleminde açık kaynak kodlu CBS yazılımlarından QGIS 2.14.8, hâlihazır veriler ile analizlerin gerçekleştirilmesi ise ArcGIS 10.1 tercih edilmiştir.

\subsection{Metot}

Çalışma yöntemi; veri hazırlama, güzergâh analizleri ve kontrol/değerlendirme olarak 3 temel aşamadan oluşmaktadır (Şekil 2).

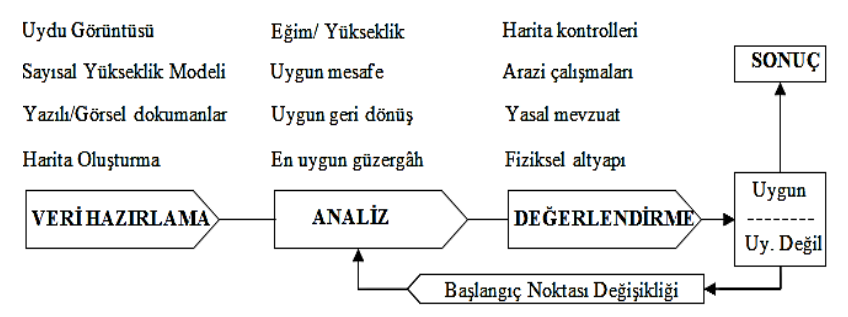

Şekil 2. Yöntem akış şeması

Birinci aşamada çalışma alanına ait altlık harita oluşturmak üzere açık erișimde olan Sentinel 2A uydu görüntüsünün $10 \mathrm{~m}$ çözünürlüklü 2-3-4 ve 8 . bantları kullanılmış, QGIS yazılımı kullanılarak sanal raster oluşturulmuştur. Ardından sayısal yükseklik modeli ile aynı projeksiyona dönüştürülerek çakıştırma işlemi gerçekleştirilmiştir.

Analiz aşamasında ise öncelikle sayısal yükseklik modelleri üzerinden eğim grupları belirlenmiş ve eğim haritaları oluşturulmuştur. Eğim haritaları kullanılarak sırasıyla uygun mesafe (CD), uygun geri dönüș bağlantısı (CBL) ve en uygun güzergâh (LCP) analizleri yapılmıștır. CD (Cost Distance); haritanın en küçük birimi olan rasterdeki her hücre için, bir maliyet yüzeyindeki en düşük biriken maliyete dayanarak en yakın kaynağa olan mesafeyi vermektedir. Öklid mesafesi ile benzerlik gösterir, ancak bir konumdan diğerine gerçek mesafeyi hesaplamak yerine, maliyet uzaklığı araçları her bir hücreden en yakın kaynak konumuna en kısa ağırlıklı mesafeyi belirler. CBL (Cost Back Link) bağlantısı ise, en düşük maliyetli kaynağa giden en düşük birikimli maliyet yolundaki bir sonraki hücre olan komşuyu tanımlar. Geri dönüş bağlantısını hesaplamak için kullanılan algoritma her hücreye 0 ile 8 arasında bir kod atar. 0 değeri, kaynak hedefi göstermek için kullanılır. 1'den 8'e kadar olan değerler, yönü sağdan başlayarak saat yönünde kodlar. Kaynak hedefe ulaşabilmek için en uygun hücreleri birbirine bağlayarak ilerler. Son analiz ise, CD ve CBL analizleri sonucu oluşan haritalar kullanılarak üretilen LCP (Least Cost Path) analizidir. Bu analiz, bir kaynak ile varış yeri arasında uygun maliyetli bir rota belirlemek için bir alan için maliyet ağırlıklı mesafe ve yön yüzeylerini kullanır. Çalıșma kapsamında, belirlenen başlangıç noktalarından Termessos Antik Kenti'ne (bitiş noktasına) en düşük eğim grupları kullanılarak en kısa güzergâhın otomatik olarak belirlenmesinde birbiriyle bağlantılı bu üç analiz kullanılmıştır. Başlangıç noktalarının belirlenmesinde, otoyollara yakınlık, araçla ulaşılabilirlik, düz ve düze yakın eğim ve yerleşim birimlerine yakınlık ölçütleri dikkate alınmıştır.

Son aşamada ise, elde edilen raster formatlı güzergâhlar, vektör formatına dönüştürülerek uzunlukları otomatik olarak hesaplatılmış ve zorluk dereceleri sınıflandırılmıştır. Zorluk derecesi sinıflandırmasında Kirazcıoğlu vd. (2013)'den yararlanılmış, uzunluk, eğim ve yürüyüş süresi arttıkça zorluk derecesinin artacağı öngörülmüştür 
[20]. Harita üzerinden, oluşturulan güzergâhların uygun olup olmadı̆̆ı, analizlerde uydu görüntüsü kaynaklı herhangi bir hata olup olmadığı, güzergâh boyunca doğa yürüyüşünü engelleyebilecek bir durumun varlığı (akarsu, sazlık-bataklık, yaban hayatı geliștirme sahası vb.) gibi konular arazi çalışmaları ile kontrol edilmiştir. Kontrol sonucunda uygun olmayan güzergâhlar için başlangıç noktaları değiştirilerek yeniden analize tabi tutulması öngörülmüş ancak arazi gözlemlerinde bir sorunla karşılaşılmamıştır. Son olarak analiz sonucu elde edilen ve uygun görülen güzergâhlar yasal mevzuat açısından değerlendirilmiş ve tartışılmıştır.

\section{Bulgular}

Bir noktadan başka bir noktaya ulaşmak üzere, güzergâh boyunca var olan doğal ve kültürel değerleri göstermek, bilinç oluşturmak, sağlıklı yaşamak, doğa ile iç içe olmak üzere tekli veya gruplar halinde yapılan Doğa yürüyüşleri için seçilen Güllük Dağı Milli Parkı, sahip olduğu doğal-kültürel ve tarihi yapısı yanında fiziksel ve iklimsel özellikleri ile hiking planlaması için uygun olduğu öngörülmektedir (Şekil 3). Bölgenin deniz seviyesinden olan yüksekliği yaklaşık 250 m'lerde başlamakta, Termessos Antik Kenti'nin kurulu olduğu kısımda $1100 \mathrm{~m}$ ve en yüksek bölgede ise 1650 m'lere ulaşmaktadır. Yörede kızılçam ve maki florası hâkimdir. Keçi, karakulak, kaya sansarı, kartal, geyik gibi birçok hayvan türü bölgede barınmakta ve turistlerin ilgisini çekmektedir.

Termessos Antik Kenti'ne ulaşmak üzere, milli parka en yakın düz ve düze yakın eğimde bulunan yerleşim birimleri Düzlerçamı, Bayatbademleri ve SöğütçükKargılı olarak belirlenmiş, harita üzerinde koordinatlandırılmıştır (Şekil 4a). Ardından sayısal yükseklik modeli üzerinden eğim grupları oluşturularak eğim haritası üretilmiştir (Şekil 4b). Eğim haritasındaki bilgiler doğrultusunda, milli

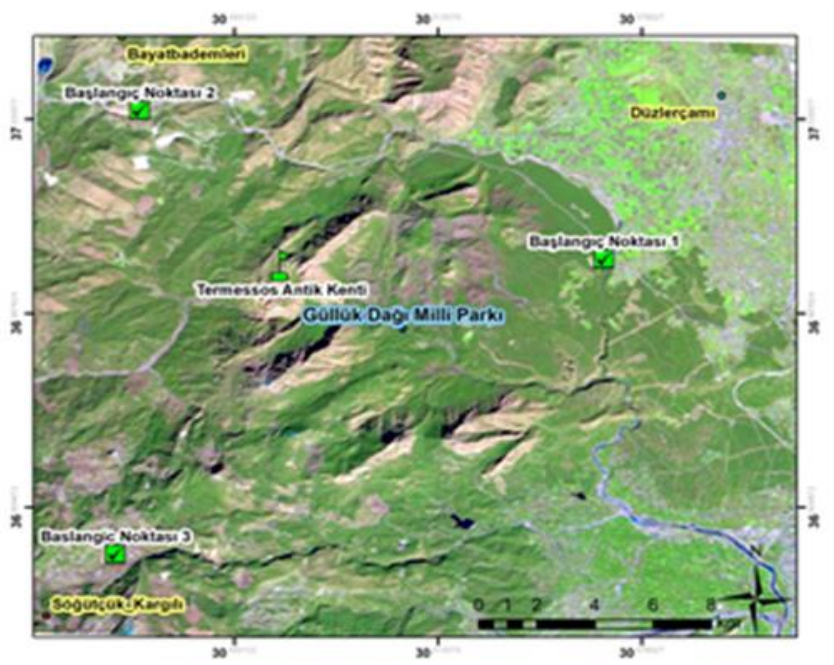

Şekil 4. (a) başlangıç noktaları konumları, (b) bölgenin eğim grupları
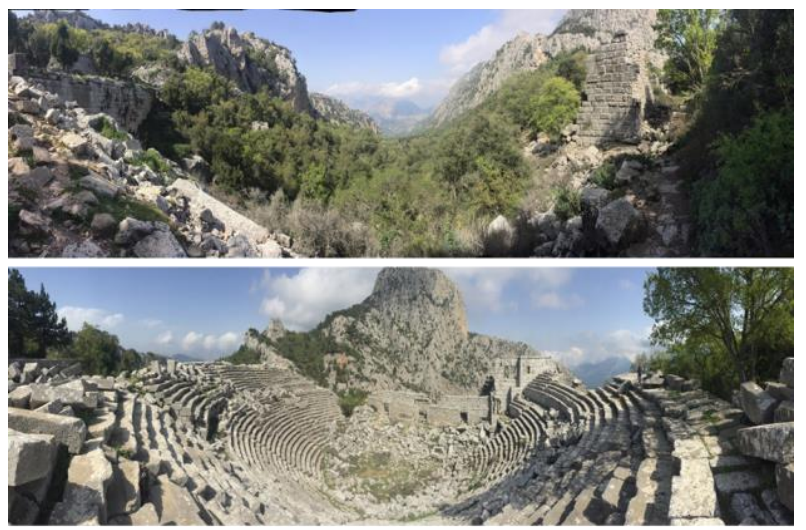

Şekil 3. Güllük Dağı Milli Parkı ve Termessos Antik Kenti

parkın kuzey, güney ve batısı yüksek eğim grupları ile çevrilmişken doğusunda geniş düzlükler bulunmakta, ancak bu düzlükler çok yüksek eğimle zirveye bağlanmaktadır. Termessos Antik Kenti, geneli \%30 ve üstünde olan bir eğim grubunun ardından \%3-4 ve 4-5’lik alanda konuşlanmaktadır.

Elde edilen eğim haritası üzerinden Düzlerçamı lokasyonu başlangıç noktası 1 olarak, Bayatbademleri lokasyonu başlangıç noktası 2 olarak ve SöğütçükKargılı lokasyonu başlangıç noktası 3 olarak CD analizine tabi tutulmuştur (Şekil 5a). Bu noktalardan varış noktası olarak atanan Termessos Antik Kenti'ne en uygun maliyetli (düz eğimli ve kısa mesafeli) yolun mesafesi bu analizle belirlenmiştir. Ardından CD raster görüntüsü kullanılarak işaretlenen başlangıç ve bitiş noktaları için ayrı ayrı CBL analizi uygulanmıştır (Şekil 5b).

Doğa yürüyüşleri kapsamında belirlenen ve analize tabi tutulan 3 başlangıç noktası, birbirinden farklı özelliklere sahiptir. Güllük Dağı'na kısmen yakın olan ve antik kentin kuzeydoğusunda bulunan Düzlerçamı başlangıç noktası, diğer noktalara göre daha yoğun kullanılan ve düz bir bölgedir. Yerleşim alanlarına oldukça yakın ve turistler bakımından bilindik bir

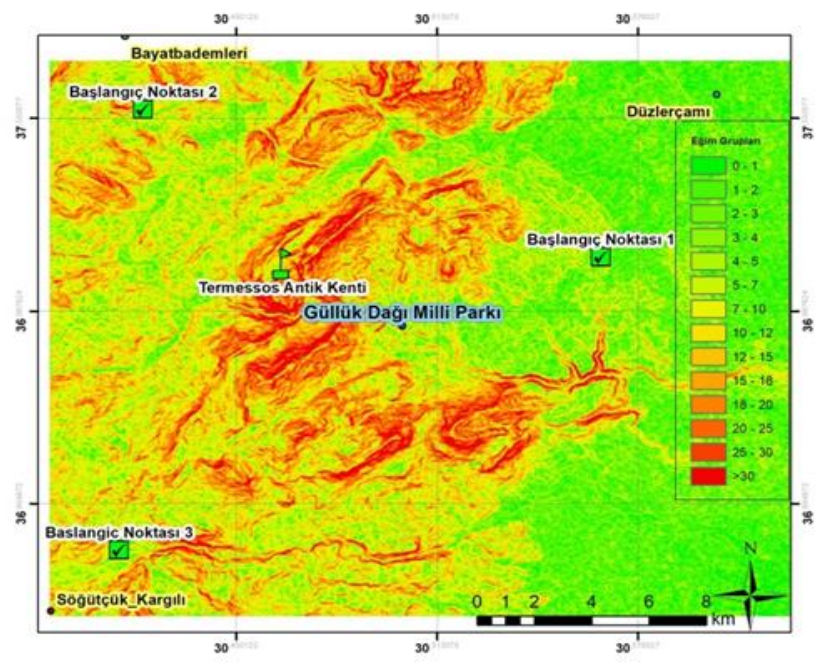



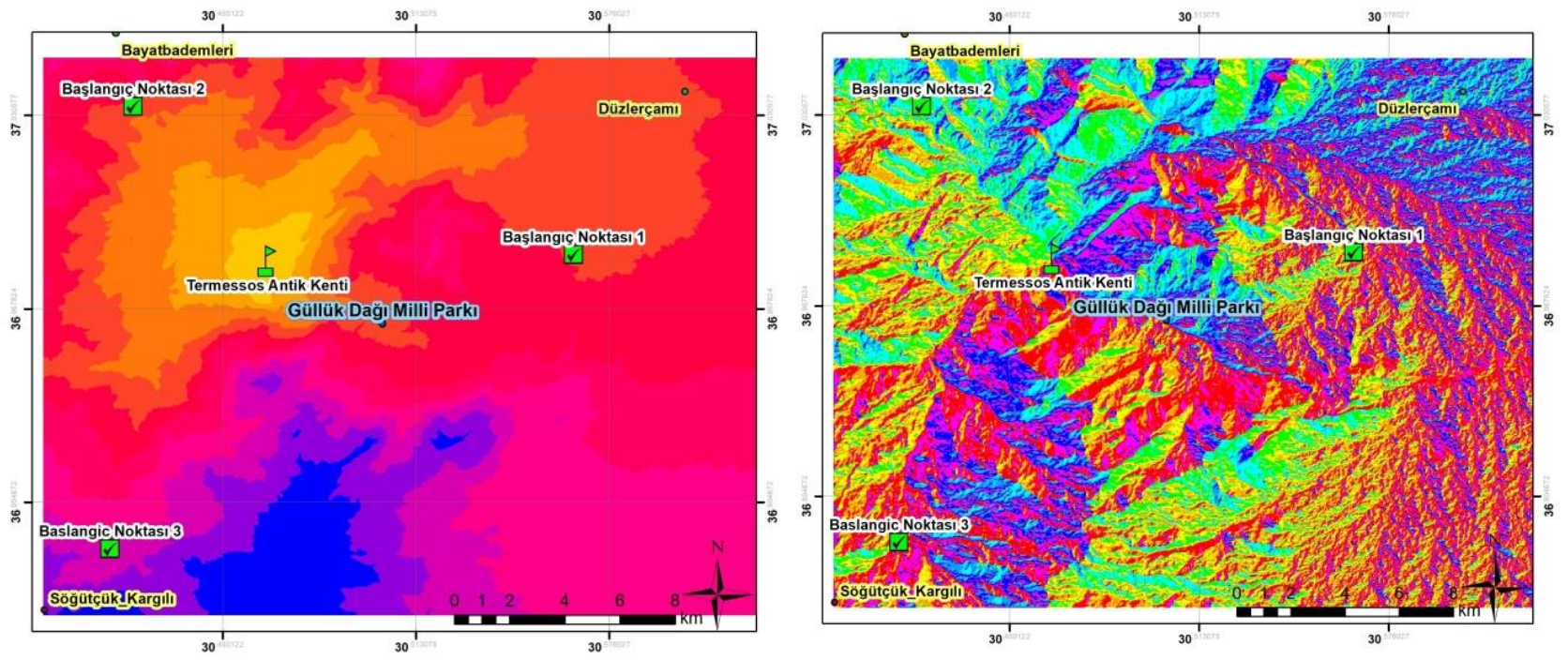

Şekil 5. (a) Cost Distance (CD) raster, (b) Cost Back Link (CBL) Raster

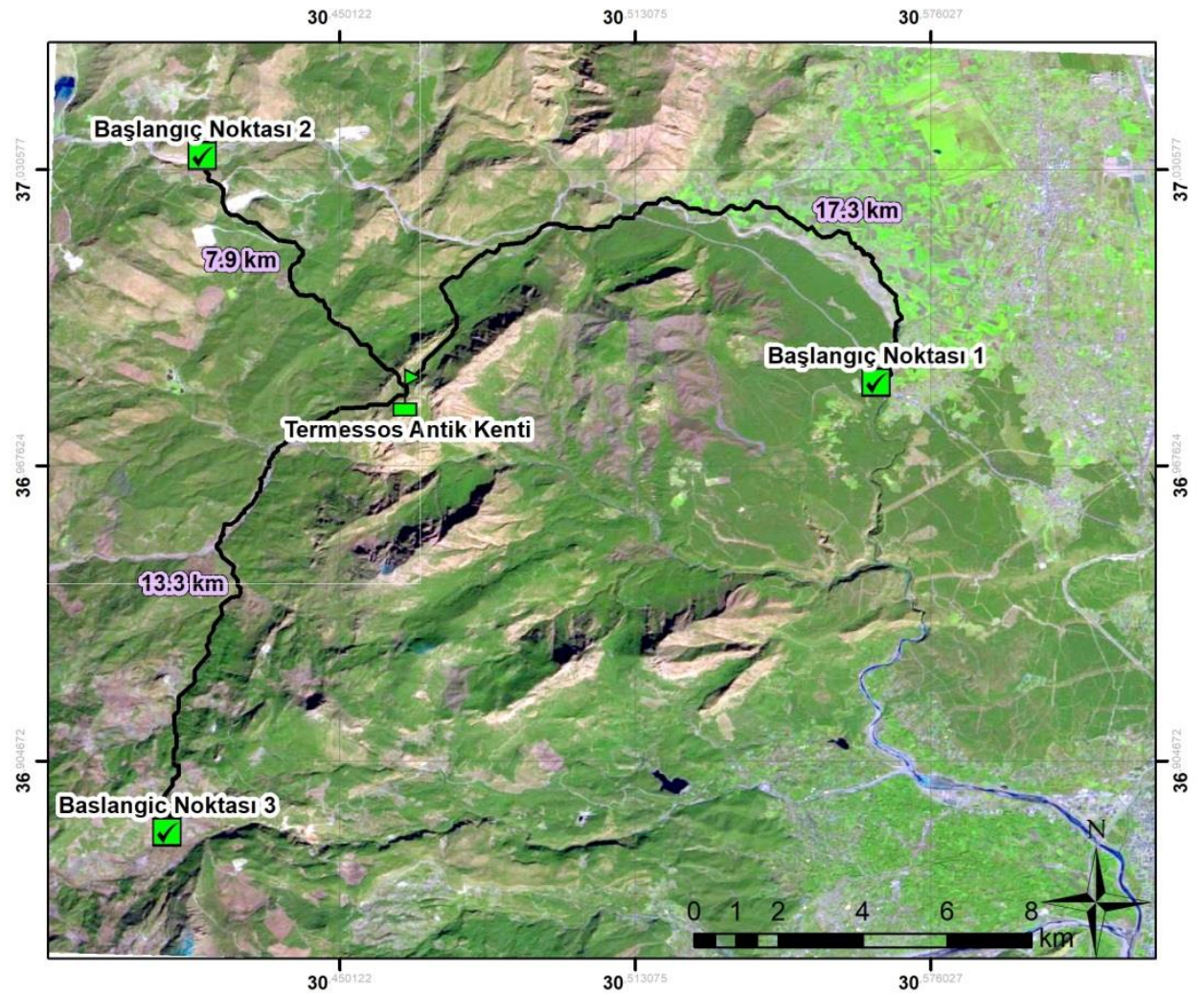

Şekil 6. LCP algoritması ile oluşturulan doğa yürüyüşü güzergâhları

bölgedir. İkinci nokta ise, bölgenin kuzey batısındaki Bayatbademleri'dir. Korkuteli ilçesine bağlı bir mahalle olarak az nüfuslu ve iklimi Antalya merkezine göre serttir. Diğer nokta ise, SögütçükKargılı bölgesi olarak milli parkın güneybatı yamaçlarındadır. Bu bölge diğerlerine göre zorluk derecesi bağlamında ağır bir bölgedir. Araçla ulașım sağlandıktan sonra doğa yürüyüşü yapılmasına uygundur. Bu başlangıç noktalarından, antik kente ulaşmak üzere ayrı ayrı daha önceden elde edilen CD ve CBL rasterleri kullanılarak LCP analizi uygulanmıștır. LCP önceki iki analizi birlikte değerlendirerek en uygun güzergâhı girdilere bağlı olarak oluşturan sonuç ürünüdür (Şekil 6).
LCP analizi sonucu belirlenen başlangıç noktalarından, Güllük Dağı'nı kullanarak Termessos Antik Kenti'ne ulaşan güzergâhlar eğimin en düşük olduğu kısımlardan geçmektedir. Her bir güzergâh için ortalama eğim \%3 ile \%10 arasındadır. Ancak algoritma en kısa ve efektif güzergâhı tercih ettiği için bazı noktalarda eğim, kısa alanda olmak koşuluyla $\% 10$ un üzerine de çlkmaktadır. Oluşturulan güzergâhlar, 1970 yılından beri Milli Park Statüsünü koruyan bölgenin, doğal ve tarihi değerlerini en kısa ve en etkili şekilde gezdirmektedir. Bu güzergâhların faaliyete geçmesi aşamasında da doğal materyallerin ve yürüyüş genişliğinin dikkate alınması gerekliliği, yörenin doğal ve kültürel yapısını bozmama adına 
önem arz etmektedir. Başlangıç noktalarından itibaren otomatik olarak oluşturulan güzergâhlar, doğa yürüyüşleri için uygun olan mesafelerdedir. Zorluk derecesine göre sinıflandırıldığında ise, 17,3 km'lik 1. güzergâh, düşük eğimli, az iniş-çıkışa sahip ve toplam mesafenin büyük bir kısmı açık ve geniş alanda kat edilebileceğinden dolayı kolay-orta zorluktadır. Bu güzergâh, sağlık problemi olmayan, yürüyüşlere yeni başlayan veya birkaç hafif yürüyüşe katılmış herkes için uygun niteliktedir. 13,3 km'lik 3. güzergâh, çoğunlukla sık ormanlardan geçmekte, bol eğimli, ani yükselme-alçalmaların olduğu zor niteliğe sahiptir ve tecrübeli, kondisyonlu, deneyimli yürüyüşçüler için uygundur. Diğer güzergâhlara göre yükselmelerin eğimin fazla olduğu kısa mesafeli 2 . güzergâh ise orta zorlukta ve $7,9 \mathrm{~km}$ 'dir. Yürüyüş deneyimi ve iyi kondisyonu olanlar için uygun görülmektedir. Analizler sonucu belirlenen güzergâhlar, gerek eğim gerekse de fiziksel koşulları ve doğal/kültürel değerleri bakımından doğa yürüyüşleri için uygun niteliktedir.

\section{Tartışma ve Sonuç}

Bu çalışmada, Dijkstra algoritması temeline dayanan ve graph teorisi mantığı ile çalışan LCP analizi kullanılarak doğa yürüyüșü için bașlangıç ve varıș noktaları arasındaki en uygun güzergâhlar otomatik olarak belirlenmiștir. Güzergâhlar, eğimin en düşük olduğu ve iki nokta arasındaki en kısa yolu bulmaya yönelik olarak belirlenmiștir. LCP analizi CBS teknolojileri ile birlikte güzergâhları eğim faktörü yanında arazi örtüsü, toprak yapısı, anıt niteliğindeki bölgeler vb. gibi diğer birçok faktörü de birlikte değerlendirebilecek potansiyele sahiptir. Ancak bu çalıșma sadece eğim ve en kısa yola odaklanmıștır.

LCP analizi; taşımacılık [21], doğa koruma [22], coğrafya [23], yaban hayatı [24], peyzaj planlama [25], arkeoloji [26], karayolu planlaması [27] gibi birçok alanda hızlı ve yüksek doğrulukta sonuçlar vermesi sebebiyle tercih edilmektedir. $\mathrm{Bu}$ analiz, bilgiyi merkezi bir konumda tutan merkezi bir yönlendirme algoritması olarak tanımlanan [28] Dijkstra algoritmasını kullanır. Amaç, belirli bir kaynak düğümden diğer tüm düğümlere kadar en düşük maliyetli yolu bulmaktır. Bu algoritma, çoklu yinelemelerde maliyeti optimize ederek bir başlangıç noktasından bir varış noktasına en düşük maliyetli yolları belirler. Çalışma kapsamında doğa yürüyüşü için belirlenen başlangıç noktaları, Dijkstra algoritmasına dayanan LCP analizi ile varış noktası olan Termessos Antik Kenti'ne en uygun eğim ve en kısa yolu kullanarak bağlanmıştır. Bölgedeki varış noktasina ulaşan bir mevcut güzergâh bulunmaktadır. 9 km'si araç yolu ve 1 km'si yürüyüş yolu olan bu güzergâh, analiz sonucu oluşturulan 1 . güzergâh ile örtüşmektedir. Elde edilen güzergâhlar, Dijkstra algoritmasının, yükselen alternatif turizm faaliyetleri kapsamında doğa yürüyüşü rotalarının belirlenmesinde kullanılabileceğini, girdilere bağlı olarak yüksek doğrulukta sonuçlar verdiğini, özellikle planlama aşamasında hızlı bir karar alma mekanizması olarak tercih edilebilir nitelikte olduğunu göstermektedir.

$\mathrm{Bu}$ çalışma, alternatif turizm potansiyeli bulunan bölgelerin yürüyüş güzergâhlarının planlanmasında, karar alıcılara yön verecek ilk aşama niteliğindedir. Yürüyüş güzergâhı belirlemede en önemli faktör olan eğimi ele almaktadır. Bu aşamadan sonra bölgenin sahip olduğu imkânlar, manzara, riskler, habitatlar vb. özelliklerinin de ilgili meslek disiplinleri ile birlikte ele alınıp, eğim faktörü sonucu elde edilen güzergâh ile kombine edilmesi daha sağlıklı sonuçlar verecektir.

Çalışma yasal düzenlemeler ışı̆̆ında değerlendirildiğinde, planlanması ve uygulanmasında bir sakınca bulunmadığı görülmektedir. Türkiye'de Milli parklara yönelik yasal mevzuat Milli Parklar Kanunu ile düzenlenmiştir. Kanunun 2. Maddesinin a bendinde Milli park; "bilimsel ve estetik bakımından, milli ve milletlerarası ender bulunan tabii ve kültürel kaynak değerleri ile koruma, dinlenme ve turizm alanlarına sahip tabiat parçaları" olarak tanımlanmaktadır. Çalışmanın yürütüldüğü Güllük Dağı Milli Parkı, tabii ve kültürel değerleri ile ön plana çıkmakta, turizm alanlarına sahip olmasıyla da yoğun ilgi görmektedir. Özellikle alternatif turizmin geliștirilmesi kapsamında doğa yürüyüșleri için önemli bir potansiyeli vardır. Ancak bu faaliyetin geliştirilmesinde doğa koruma öncelikleri dikkate alınmalıdır. Bunun yanında halkın katılımının sağlanması ve alternatif turizm faaliyetlerinin desteklenmesi bölge açısından önem taşımaktadır [29]. Dolayısıyla planlanan yürüyüş güzergâhları doğa ile uyumlu niteliktedir. Kanunun 7. Maddesinde Milli parklarda, planlarına uygun olması şartıyla, kamu kurum ve kuruluşları tarafından yapılacak her türlü plan, proje ve yatırımlara izin verilebileceği bildirilmektedir. Doğa yürüyüşleri için ihtiyaç olan sadece yürüme genişliğinde zeminin düzenlenmesi ve belirli aralıklarda dinlenme mekânlarının oluşturulması olduğu için çalıșma yasal mevzuata uygundur. [30] Cetin ve Sevik (2016) özellikle Milli Parklarda yapılacak rekreasyonel faaliyetlerde denge unsurunun gözetilmesi ve olumsuz çevresel etkilerin yaratılmaması, çevreye saygılı olunması gerektiğini belirtmiştir. Doğa yürüyüşleri ve yürüyüş rotaları, bölgenin tanıtımına sağladığı katkı yanında doğal ve kültürel çevreye de olumsuz etki vermemektedir.

$\mathrm{Bu}$ çalıșma ile turizm faaliyetleri ve turizm gelirleri kapsamında Türkiye'nin öncü kenti olan Antalya'nın alternatif turizm faaliyetlerinin desteklenmesi hedeflenmiştir. Tarihi ve kültürel değerlerin tanıtılmasında, doğaya zarar vermeyen ve sağlıklı yaşamı destekleyen doğa yürüyüșü için en uygun rotalar hızlı ve yüksek doğrulukta otomatik olarak belirlenebilmiştir. Bu yöntem, bölgedeki diğer tarihituristik alanlar için uygulanabilir niteliğe sahiptir. 
Yöntem girdilere bağlı olarak en uygun güzergâhları tespit edebilmekte, dolayısıyla turizm planlamasında ve alternatif turizm stratejilerinde karar vericilere yol gösterebilecek nitelik taşımaktadır.

\section{Kaynakça}

[1] Aydın, F., Çepni, O., Turgut, T., 2017. Investigation of Alternative Tourism Types and Sights via Geographic Information Systems: The Exaple of Safranbolu. ISPRS Annals of the Photogrammetry, Remote Sensing and Spatial Information Sciences, Volume IV-4/W4, pp. 97100.

[2] Nunkoo, R., Fung So, K.K., 2016. Residents' Support for Tourism: Testing Alternative Structural Models. Journal of Travel Research, 55(7) 847-861.

[3] Özer, Ö., Avcl, M., Karakuş, N., 2016. A Study For the Evaluation of Alternative Tourism Opportunities in Fethiye Destination. Journal of Tourism and Gastronomy Studies 4(1), 21-26.

[4] Mihalic, T. 2016. Sustainable-responsible tourism discourse - Towards 'responsustable' tourism. Journal of Cleaner Production, 111, 461-470.

[5] Jovicic, D. 2016. Cultural tourism in the context of relations between mass and alternative tourism. Current Issues in Tourism, 19 (6) 605612.

[6] Baum, T. 1998. Taking the exit route: Extending the tourism area life cycle model. Current issues in tourism, 1,(2), 167-175.

[7] Burns, P. M. 2004. Tourism planning: A third way?. Annals of Tourism Research, 31(1), 24-43.

[8] Stonich, S. C. 1998. Political ecology of tourism. Annals of tourism research, 25(1), 25-54.

[9] Varjú, V., Suvák, A., Dombi, P. 2014. Geographic Information Systems in the service of alternative tourism-methods with landscape evaluation and target group preference weighting. International Journal of Tourism Research, 16(5), 496-512.

[10] Rodrigues, Á., Kastenholz, E., Rodrigues, A. 2010. Hiking as a relevant wellness activity-results of an exploratory study of hiking tourists in Portugal applied to a rural tourism project. Journal of Vacation Marketing, 16(4), 331-343.

[11] Chen, J.S., Prebensen, N., Huan, T.C., 2008. Determining the Motivation of Wellness Travelers, Anatolia, 19(1), 103-115.

[12] Hugo, M. L. 1999. A comprehensive approach towards the planning, grading and auditing of hiking trails as ecotourism products. Current Issues in Tourism, 2(2-3), 138-173.
[13] Terh, S. H., Cao, K. 2018. GIS-MCDA based cycling paths planning: a case study in Singapore. Applied geography, 94, 107-118.

[14] Selim, S., Sönmez, N. K. 2017. Coğrafi bilgi sistemleri tabanlı rota planlama: Likya Bölgesi Idebessos Antik Kenti. Türkiye Ormancllı Dergisi, 18(4), 302-308.

[15] Yang, H., Cherry, C. R., Zaretzki, R., Ryerson, M. S., Liu, X., Fu, Z. 2016. A GIS-based method to identify cost-effective routes for rural deviated fixed route transit. Journal of Advanced Transportation, 50(8), 1770-1784.

[16] Abousaeidi, M., Fauzi, R., Muhamad, R. 2016. Geographic Information System (GIS) modeling approach to determine the fastest delivery routes. Saudi journal of biological sciences, 23(5), 555-564.

[17] Pitman, A., Zanker, M., Gamper, J., Andritsos, P., 2012. Individualized Hiking Time Estimation. 2012 23rd International Workshop on Database and Expert Systems Applications, Vienna, 2012, pp. 101-105.

[18] Alçıtepe, E., 1998. Termessos Milli Parkı (Antalya) florası üzerinde bir araştırma. Akdeniz Üniversitesi, Fen Bilimleri Enstitüsü, Yüksek Lisans tezi, 194 s, Antalya

[19] Kültür ve Turizm Bakanlığı, 2019. Kültür Varlıkları ve Müzeler Genel Müdürlüğü, Güllük Dağl-Termessos Milli Parkl, Antalya. http://www.kulturvarliklari.gov.tr/TR44417/g ulluk-dagi-termessos-milli-parki-antalya.html (Erişim tarihi: 13.03.2019)

[20] Kirazcıoğlu, Ö., Batur, M., Şafak, İ., Boza, Z., Öner, H.H. 2013. Doğa Yürüyüș Güzergâhlarının İncelenmesi (Ovacık-Sinancılar Örneği). T.C. Orman ve $\mathrm{Su}$ İşleri Bakanlığı, Orman genel Müdürlüğü, Ege Ormancılık Araştırma Enstitüsü Müdürlüğü, Teknik Bülten No:55, Müdürlük Yayın No:73, 113s.

[21] Kumari, S. M., Geethanjali, N. 2010. A survey on shortest path routing algorithms for public transport travel. Global Journal of Computer Science and Technology, 9(5), 73-76.

[22] Bagli, S., Geneletti, D., Orsi, F. 2011. Routeing of power lines through least-cost path analysis and multicriteria evaluation to minimise environmental impacts. Environmental Impact Assessment Review, 31(3), 234-239.

[23] Atkinson, D. M., Deadman, P., Dudycha, D., Traynor, S. 2005. Multi-criteria evaluation and least cost path analysis for an arctic all-weather road. Applied Geography, 25(4), 287-307.

[24] LaRue, M. A., Nielsen, C. K. 2008. Modelling potential dispersal corridors for cougars in midwestern North America using least-cost path methods. ecological modelling, 212(3-4), 372381. 
[25] Teng, M., Wu, C., Zhou, Z., Lord, E., Zheng, Z. 2011. Multipurpose greenway planning for changing cities: A framework integrating priorities and a least-cost path model. Landscape and urban planning, 103(1), 1-14.

[26] Diwan, G. A., Doumit, J. 2017. The BerytusHelıopolıs Baalbak Road in the Roman Period: A least cost path analysis. Mediterranean Archaeology \& Archaeometry, 17(3), 225-241.

[27] Sarl, F., Sen, M. 2017. Least cost path algorithm design for highway route selection. International
Journal of Engineering and Geosciences, 2(1), 18.

[28] Rees, W. G. 2004. Least-cost paths in mountainous terrain. Computers \& Geosciences, 30(3), 203-209.

[29] Zhang, J. Y., Zhang, Y. J. 2017. On public participation in the construction of national parks. Biodiversity Science, 25(1), 80-87.

[30] Cetin, M., Sevik, H. 2016. Evaluating the recreation potential of Ilgaz Mountain National Park in Turkey. Environmental monitoring and assessment, 188(1), 52. 